\title{
Tourists and attitudes to air-conditioning in the tropics
}

\author{
Zbigniew Bromberek* \\ Department of Architecture, The University of Q ueensland, Brisbane 4072, A ustralia
}

\begin{abstract}
A survey of tourists visiting Cairns in northern Australia showed significant dissatisfaction with the indoor climate conditions provided. The rationale for a year-round fully controlled environment is questioned when, in the hot and humid weather of the tropical summer, almost half of the surveyed tourists did not perceive these conditions to justify the use of air-conditioners. Responses in the survey suggest that tourists' needs in this respect are markedly different from those perceived to exist by tourist resort developers and operators.
\end{abstract}

KEY WORDS: Tourists · Tropics · Accommodation · Attitudes

\section{INTRODUCTION}

There are 2 major factors contributing to the perceived quality of architecture. The first is the quality of the architectural design itself. The second is the assessment and opinions of the prospective users. The latter issue remains largely unexplored.

Both factors should be linked with the relevant practical knowledge based on up-to-date scientific theory. Nevertheless, people lacking either knowledge or experience (or both) in dealing with tropical climates and their related problems prepare a vast majority of the resort designs intended for tropical regions. This is not surprising when one realises that most projects for the tropics are commissioned by large corporations very often multinational - and prepared by large architectural companies, all operating from outside the tropics. Even more evident is the designers' lack of knowledge and experience concerning the diverse and complex problems of human responses to temporary changes of climate - in particular, to the changes so brief that they exclude any possibility of a full acclimatisation. It must be noted that habits, established preferences, reasons for travelling to the tropics and related expectations and perceptions all influence the requirements to which the design should respond. Equally important is that the design should achieve the goal adequately and efficiently - without wasting

*E-mail: z.bromberek@mailbox.uq.edu.au scarce resources or polluting the highly sensitive environment.

This paper draws on the results of an opinion survey carried out at the Cairns International Airport, Far North Queensland, Australia, in late December 1994. The survey was intended as a tool to learn about the attitudes of a group of international and interstate travellers towards accommodation conditions in the climatically demanding area. Cairns is located in the centre of northern Queensland and is popularly perceived as the 'tourist capital' of the region. The survey was expected to contribute to a foundation on which designers and tourist operators could establish their future strategies. It was expected to become an agent for change in their current beliefs, which presently result in promoting solutions that are wasteful and potentially damaging to the natural environment. Finally, it was expected that the survey could provide evidence to support some common knowledge, built mostly on anecdotal examples, about human responses to tropical climates.

\section{METHOD}

The survey gathered information on the perception of environmental comfort among tourists coming to Far North Queensland from a variety of climatic regions. To avoid preconceptions and biases, the survey had to be conducted in a place guaranteeing access to a large 
number of international visitors representing a broad range of cultural, behavioural and financial backgrounds, and after they had had the longest possible exposure to local conditions.

It was believed that the most appropriate location to conduct the survey was at the Cairns International Airport, and preferably in its departure lounge. Cairns' airport was at the time the only internationally accessible airport in the whole region, since Qantas and Garuda Indonesia had discontinued their international flights to Townsville. The airport location for the survey ensured a great variety of tourists who could be included in a sample. Virtually all international tourists arrive in and depart from Australia by air. Thus, no matter what the accommodation preferences and financial capacities of visitors to Cairns were, all of them went through the airport's departure lounge. The usual organisation for air travel required passengers to remain idle for at least half an hour before departure. This factor removed much of the anxiety that would normally be associated with a survey interview situation.

The intended time frame of the survey was approximately $5 \mathrm{~d}$ during the week from 18 to 24 December 1994, a period intentionally chosen as part of the typically hottest and most humid season in Cairns. It was assumed that responses to a similar survey conducted at any other time, when temperatures and humidity levels are lower and the sea is open to swimming outside installed 'sting enclosures', ${ }^{1}$ would be less favourable to the use of powered air-conditioning systems.

The opinion survey was carried out by collecting responses to a limited number of questions contained in a 1-page questionnaire and conducting informal interviews. Questionnaires were distributed among passengers departing from Australia. After approval from Cairns Port Authority, the survey was conducted by the author alone, thus minimising any disturbance either to departing tourists or to the operation of the airport. For sampling, a 'purpose-at random' method was chosen: the time of the survey and representative flight destinations were chosen and passengers were then selected at random. Tourists were approached individually in the departure lounge. After a few words of introduction ${ }^{2}$ they were asked to fill in a questionnaire. In addition, beginning with the second day, they were also asked if they were Queensland residents and if they stayed in the Cairns region overnight (an

\footnotetext{
${ }^{1}$ Coastal waters north of $22^{\circ} \mathrm{S}$ are infested with dangerous box jellyfish Chironex fleckeri (also known as 'sea wasp' or 'marine sting') from November to mid-M arch. Easier access to the sea (from any point on the beach) can be considered an improved possibility of thermal self-regulation and hence lowers the impact that the thermally stressful conditions could otherwise have
}

affirmative answer to the former question or a negative to the latter excluded them from the sample), before the questionnaires were handed to them. The respondents were given a few minutes before the questionnaires were collected. This procedure ensured a very high $(93.6 \%)$ rate of returns.

The questionnaire for the survey was prepared in 3 language versions: English/J apanese, English/Chinese and English/German. The choice of languages appeared to match well the linguistic abilities of tourists at Cairns Airport. However, on a few occasions communication of the questionnaire's contents to tourists using other languages was impossible. These difficulties applied to several travellers from Spain and Italy. ${ }^{3}$

The survey intentionally did not suggest or include questions on the availability of alternatives to powered air-conditioning. Tourists were supposed to assess the conditions that were actually provided and express their feelings about the situation as it was.

\section{BACKGROUND WEATHER CONDITIONS}

Meteorological data for the first 20 days of December, gathered by the Bureau of M eteorology at Cairns airport (geographical location: $16^{\circ} 53^{\prime} 15^{\prime \prime} \mathrm{S}, 145^{\circ} 45^{\prime}$ 13" E; elevation: $3.0 \mathrm{~m}$ ), are presented in Table 1. Weather conditions in this period constitute the outdoor climate background to the relevant experiences of almost $93.5 \%$ of the surveyed tourists. In other words, Table 1 shows conditions to which $93.5 \%$ of the survey sample were exposed to during their entire stay in the region. The remaining $6.5 \%$ - those who stayed there for more than $3 \mathrm{wk}$ - experienced the conditions described in Table 1 during the part of their stay immediately preceding their departure.

The data in Table 1 show that the period chosen for the survey was preceded by a typical early summer weather: not excessively hot during the day, moderately warm at night, with average (for the region) to high maximum relative humidity and moderate rainfall (cf. Climatic Averages Australia 1975). In general, the weighted average temperatures (both maximum and minimum) of the $3 \mathrm{wk}$ were lower than the corresponding $10 \mathrm{yr}$ averages for the month of December, the relative humidity was higher and rainfall was lower. The 'Big Wet', as the monsoonal season is called

\footnotetext{
${ }^{2}$ Tourists were told about the purpose of the survey and about the nature of the questions to be asked. An effort was made to use the language of the traveller concerned

${ }^{3}$ Verbal communication with these tourists was possible, but the principle of not interfering with the process of preparing answers excluded use of questionnaires
} 
Table 1. Maximum and minimum air temperature, relative humidity and rainfall at Cairns Airport M eteorological Station in the period immediately before the survey (1 to 20 December 1994)

\begin{tabular}{|lcccccrc|}
\hline & \multicolumn{2}{c}{ Air temperature } & \multicolumn{2}{c}{ Air temperature } & \multicolumn{2}{c}{ Relative humidity } & Rainfall \\
& Maximum $\left({ }^{\circ} \mathrm{C}\right)$ & Time & Minimum $\left({ }^{\circ} \mathrm{C}\right)$ & Time & Maximum $(\%)$ & Time \\
Recorded extremes & $27.7-32.4$ & $11: 00-15: 29$ & $20.1-23.6$ & $00: 34-07: 08$ & $79-95$ & $01: 01-14: 56^{\mathrm{a}}$ & $0.0-12.4$ \\
Weighted average & 30.8 & $13: 21$ & 21.8 & $04: 22$ & 87 & $06: 22$ & 2.2
\end{tabular}

a One-time occurrence of maximum relative humidity at 23:06 h was disregarded as it was fairly close to 01:01 h as shown here. On the other hand, inclusion of the $2 \mathrm{~h}$ gap would distort the weighted average

in Australia, came to the region unusually late that summer: at the end of J anuary. The data gathered at the time of the survey show that the period chosen for the research was relatively 'dry' and 'cool' compared to the summer season's 'standards'. This was marked by distinctive differences between day (07:00 to 19:00 h) and night (19:00 to 07:00 h) (see Table 2).

It would be difficult to assess the impact that typical monsoonal weather could have had on the number of visitors and their feelings about climatic comfort/discomfort. Bookings for international travel are usually made well in advance and cancellations (due to weather) only occur in the case of extreme weather conditions. Clearly, however, climate perceptions (as recorded in the survey) could have been significantly altered if the monsoon had brought different conditions.

Until the mid-1950s, all resorts in the Cairns area were closed during the wet season (McDowell 1966). Opening these facilities for all-year operation could in part be a function of the availability of relatively cheap and reliable air-conditioning technology. However, the major role was most probably played by a better transport infrastructure allowing year-round access: allseason roads, bridges, airports, and a general shift from land/sea to air travel.

\section{SURVEY SAM PLE}

The total number of completed questionnaires was 309 . This was $14.3 \%$ of the total number of passengers (2165) embarking on international flights in Cairns at the time of the survey. It should be noted, however, that the category 'joining' (i.e. embarking for the first time) includes an unspecified number of passengers arriving in Cairns on domestic flights and then leaving on international flights the same day (passengers effectively in transit). Annual statistics of the Cairns Airport Authority show that in the 1992/93 year 30.9\% of passengers using the international terminal were transits/transfers. Taking this factor into account, the relative sample size would increase to approximately $20 \%$ of the targeted population.

The survey covered 21 flights departing for destinations in 7 countries. Table 3 shows the flights included in the survey compared to the weekly number of flights during the survey period.

The 309 respondents came from 21 countries (including Australians): Japan, UK, Singapore, Papua New Guinea, New Zealand, USA, Germany, Australia (interstate), Sri Lanka, Hong Kong, Thailand, Canada, China, Indonesia, Italy, Sweden, Spain, Switzerland, France, Ireland and Finland. Using the regional terminology employed by the Australian Bureau of Statistics, respondents came from the following areas: J apan, 177 (57.3\%); Southeast Asia including Papua New Guinea, 52 (16.8\%); Europe, 41 (13.3\%); North America, 14 (4.5\%); New Zealand, 14 (4.5\%); A ustralia (interstate), 11 (3.6\%).

Europeans seem to be under-represented in the survey when compared with annual figures. However, the peak holiday season in Europe falls in J uly-August. On the other hand, it appeared that large numbers of Papua New Guineans were coming to Cairns for winter holidays. By far, the most important - the largest and also the highest per capita spending - group of visitors to Cairns, not only during the survey period but also throughout the year, are holidaymakers from J apan.

Table 2. Average air temperature and relative humidity during the day and at night at Cairns Airport Meteorological Station in the period immediately before the survey (1 to 20 December 1994)

\begin{tabular}{|c|c|c|c|c|}
\hline & \multicolumn{2}{|c|}{ A verage air temperature $\left({ }^{\circ} \mathrm{C}\right)$} & \multicolumn{2}{|c|}{ Average relative humidity (\%) } \\
\hline & $07: 00-19: 00 \mathrm{~h}$ & $19: 00-07: 00 \mathrm{~h}$ & $07: 00-19: 00 \mathrm{~h}$ & $19: 00-07: 00 \mathrm{~h}$ \\
\hline Extremes & $23.0-29.3$ & $21.6-25.2$ & $44.8-85.7$ & $64.0-81.8$ \\
\hline Weighted average & 28.0 & 23.7 & 56.6 & 71.5 \\
\hline
\end{tabular}


Table 3. Number of flights included in the survey compared with the weekly number of international flights departing from Cairns International Airport at the time of the survey

\begin{tabular}{|lccc|}
\hline $\begin{array}{l}\text { Destination } \\
\text { country }\end{array}$ & $\begin{array}{c}\text { No. of flights } \\
\text { weekly }\end{array}$ & $\begin{array}{c}\text { No. of flights } \\
\text { surveyed }\end{array}$ & $\begin{array}{c}\text { \% of weekly } \\
\text { flights surveyed }\end{array}$ \\
\hline Japan & 28 & 11 & 39.3 \\
Papua New Guinea & 13 & 2 & 15.4 \\
Singapore & 7 & 4 & 57.1 \\
USA & 4 & 2 & 50.0 \\
Indonesia & 4 & 1 & 25.0 \\
Hong Kong & 3 & 1 & 33.3 \\
New Zealand & 2 & 0 & 0.0 \\
United Kingdom & 1 & 1 & 100.0 \\
Total: & 62 & 21 & 33.9 \\
\hline
\end{tabular}

Most of the tourists surveyed stayed in establishments rated (or estimated) at the 3star level (103, 33.3\%). Accommodations rated at the 4- and 5-star levels do not differ much and both can be classified as luxurious. This joint category attracted 173 tourists, that is $60.0 \%$, and together with 3-star establishments they accommodated 276 tourists, which was $89.3 \%$ of the total. It is not clear whether selection of accommodation standards was a preferred option or rather a result of accommodation presently available in the region. It has been argued in the tourism media that Queensland offers too many expensive higher rated hotels and resorts and too few cheaper ones. Only 33 tourists surveyed $(10.7 \%)$ stayed in places providing

\section{SURVEY RESULTS}

Most of the travellers surveyed were visiting North Queensland for holidays/tourism (276 visitors, 89.3\%) while among other reasons one of the more frequent/ important was visiting relatives or friends $(33,10.7 \%)$. This type of visit included leisure activities and travelling throughout the region-behaviour very much alike to that of tourists (see Table 4).

Tourists stay in Cairns and the surrounding region for very short periods. Among those surveyed, 151 $(48.9 \%)$ visited for only 1 to $5 \mathrm{~d}$. This length of stay exludes the possibility of any adaptation to local climate (cf. Selvamurthy 1993: p. 516 and 520). A period of 6 to $21 \mathrm{~d}$ is required for an initial adaptation to local conditions. Only 138 tourists surveyed $(44.7 \%)$ spent this time in North Queensland. However, it must be stressed that the majority of them opted for stays of less than $2 \mathrm{wk}$. Moreover, the leisurely nature of their activities (i.e. low level of physical activity) means climatic adaptation is unlikely to be achieved, even in this group. Only 20 tourists (6.5\%) stayed in the region for more than $3 \mathrm{wk}$. Thus, it can be assumed that their exposure to local conditions was sufficient-at least partially - to remove their 'bio-climatic lag', i.e. adaptation to conditions typical in their original place of residence and 'brought' with them to Queensland (see Table 4).

The preferred place to stay was a hotel $(216,69.9 \%)$ and of this 193 or $62.5 \%$ were in the city (Cairns, Townsville) itself. Less than 60 tourists $(58,18.8 \%)$ stayed in resorts, and among other places (35, 11.3\%) camping sites were mentioned in interviews. 116 tourists $(37.5 \%)$ chose a non-urban location, and almost all of them stayed on the coast. Resort-style holidays were a popular option among Europeans and Singaporeans, and to a lesser extent Papua New Guineans, A mericans and J apanese (see Table 4). accommodation of a lower standard. It was not possible to detect any trend in respect to this choice and country of origin, age, gender, etc. because too few visitors (see Table 4) represented tourists in this category.

As a consequence of the high standard of accommodation supplied, a number of affirmative responses to the question about the provision of air-conditioning was also very large: 281 respondents $(90.9 \%)$ had airconditioning provided in their rooms, and 254 (82.2\%) had air-conditioning provided also in common rooms, like foyers or dining rooms (see Table 4).

Strongly contrasting with these numbers are the responses given to the question about the necessity of air-conditioning. As many as 128 visitors (41.4\%) believed that air-conditioning their bedrooms was not required for all of the time. An even larger number of respondents $(136,44.0 \%)$ did not feel it necessary to have air-conditioning running all the time in common rooms.

To gather information on perception of indoor climate, a modified Bedford scale was used. According to Auliciems (1989, p. 6 and 12-13; see also Mclntyre 1980) the original Bedford scale is probably the most frequently used of all the thermal scales employed in comfort research.

The original Bedford scale was developed in 1936 for his Equivalent Warmth method and contained 7 grades: (1) much too warm; (2) too warm; (3) comfortably warm; (4) neither warm nor cool; (5) comfortably cool; (6) too cool; (7) much too cool.

This 7-point scale would normally be used to record a current perception of thermal conditions. However, the survey examined comfort perceptions in retrospect. It is probably easier to recollect a perception of comfort or discomfort rather than an exact magnitude of either. For this reason, the author believed that it was necessary to simplify the original scale by reducing the 7 points to 5 . This was done by merging the 4 
Table 4. A summary of survey responses

\begin{tabular}{|c|c|c|c|c|c|c|c|}
\hline Country of origin: & All & Japan & $\begin{array}{l}\text { Southeast Asia and } \\
\text { Papua New Guinea }\end{array}$ & Europe & $\begin{array}{l}\text { North } \\
\text { America }\end{array}$ & $\begin{array}{l}\text { New } \\
\text { Zealand }\end{array}$ & $\begin{array}{c}\text { Australia } \\
\text { (interstate) }\end{array}$ \\
\hline \multicolumn{8}{|c|}{ What was the purpose of your visit to the Cairns region? } \\
\hline Tourist & 276 & 165 & 46 & 39 & 8 & 13 & 5 \\
\hline Other & 33 & 12 & 6 & 2 & 6 & 1 & 6 \\
\hline \multicolumn{8}{|c|}{ How long did you stay here? } \\
\hline 1-5 days & 151 & 84 & 30 & 9 & 9 & 9 & 10 \\
\hline $6-21$ days & 138 & 86 & 19 & 25 & 3 & 4 & 1 \\
\hline More than 3 weeks & 20 & 7 & 3 & 7 & 2 & 1 & 0 \\
\hline \multicolumn{8}{|l|}{ What place did you stay? } \\
\hline Hotel & 216 & 143 & 27 & 22 & 11 & 7 & 6 \\
\hline Resort & 58 & 26 & 15 & 14 & 2 & 0 & 1 \\
\hline Other & 35 & 8 & 10 & 5 & 1 & 7 & 4 \\
\hline \multicolumn{8}{|l|}{ Where did you stay? } \\
\hline In the town & 193 & 108 & 34 & 17 & 12 & 12 & 10 \\
\hline Outside the town & 98 & 57 & 16 & 22 & 1 & 1 & 1 \\
\hline Both & 18 & 12 & 2 & 2 & 1 & 1 & 0 \\
\hline \multicolumn{8}{|c|}{ What standard did your accommodation offer? } \\
\hline ****** & 91 & 68 & 8 & 9 & 4 & 1 & 1 \\
\hline$* * * *$ & 82 & 35 & 21 & 14 & 5 & 3 & 4 \\
\hline$* * *$ & 103 & 66 & 12 & 10 & 3 & 7 & 5 \\
\hline$* *$ & 21 & 4 & 9 & 5 & 1 & 1 & 1 \\
\hline$*$ & 12 & 4 & 2 & 3 & 1 & 2 & 0 \\
\hline \multicolumn{8}{|c|}{ Was air-conditioning provided in your room? } \\
\hline Yes & 281 & 171 & 8 & 34 & 12 & 12 & 8 \\
\hline No & 28 & 6 & 44 & 7 & 2 & 2 & 3 \\
\hline \multicolumn{8}{|c|}{ Was air-conditioning provided in common rooms (e.g. foyer, dining room)? } \\
\hline Yes & 254 & 168 & 34 & 28 & 9 & 8 & 7 \\
\hline No & 55 & 9 & 18 & 13 & 5 & 6 & 4 \\
\hline \multicolumn{8}{|c|}{ In your opinion, was air-conditioning necessary in your room? } \\
\hline Yes & 181 & 105 & 31 & 24 & 8 & 6 & 7 \\
\hline Sometimes & 104 & 65 & 15 & 12 & 4 & 5 & 3 \\
\hline No & 24 & 7 & 6 & 5 & 2 & 3 & 1 \\
\hline \multicolumn{8}{|c|}{ In your opinion, was air-conditioning necessary in common rooms (e.g. foyer, dining room)? } \\
\hline Yes & 173 & 108 & 27 & 22 & 7 & 5 & 4 \\
\hline Sometimes & 95 & 60 & 12 & 9 & 4 & 5 & 5 \\
\hline No & 41 & 9 & 13 & 10 & 3 & 4 & 2 \\
\hline \multicolumn{8}{|c|}{ How did you feel indoors for most of the time, during the day? } \\
\hline Uncomfortably warm & 17 & 7 & 4 & 5 & 0 & 0 & 1 \\
\hline Comfortably warm & 70 & 30 & 15 & 11 & 2 & 7 & 5 \\
\hline Neither warm nor cool & 42 & 23 & 8 & 7 & 2 & 1 & 1 \\
\hline Comfortably cool & 147 & 89 & 23 & 16 & 9 & 6 & 4 \\
\hline Uncomfortably cool & 33 & 28 & 2 & 2 & 1 & 0 & 0 \\
\hline \multicolumn{8}{|c|}{ How did you feel indoors for most of the time, at night? } \\
\hline Uncomfortably warm & 9 & 0 & 3 & 5 & 1 & 0 & 0 \\
\hline Comfortably warm & 51 & 19 & 9 & 8 & 3 & 6 & 6 \\
\hline Neither warm nor cool & 70 & 41 & 13 & 9 & 3 & 1 & 3 \\
\hline Comfortably cool & 140 & 83 & 23 & 18 & 7 & 7 & 2 \\
\hline Uncomfortably cool & 39 & 34 & 4 & 1 & 0 & 0 & 0 \\
\hline \multicolumn{8}{|c|}{$\begin{array}{l}\text { Do you think that it would have been possible to be comfortable indoors without the help of air-conditioning, during the } \\
\text { day? }\end{array}$} \\
\hline Yes & 60 & 31 & 9 & 11 & 3 & 4 & 2 \\
\hline Sometimes & 151 & 101 & 24 & 10 & 4 & 7 & 5 \\
\hline No & 98 & 45 & 19 & 20 & 7 & 3 & 4 \\
\hline \multicolumn{8}{|c|}{ Do you think that it would have been possible to be comfortable indoors without the help of air-conditioning, at night? } \\
\hline Yes & 103 & 62 & 19 & 14 & 3 & 3 & 2 \\
\hline Sometimes & 131 & 91 & 15 & 10 & 4 & 4 & 7 \\
\hline No & 75 & 24 & 18 & 17 & 7 & 7 & 2 \\
\hline \multicolumn{8}{|c|}{ Would you come to Cairns (or similar place) knowing that air-conditioning will not be provided? } \\
\hline Yes & 144 & 64 & 32 & 23 & 8 & 10 & 7 \\
\hline No & 165 & 113 & 20 & 18 & 6 & 4 & 4 \\
\hline
\end{tabular}


extreme grades - 'much too warm/cool' and 'too warm/cool' - into new single grades 'uncomfortably warm/cool'. ${ }^{4}$

The answers given to the questions about indoor climate perception indicate that operators usually set the temperature of air-conditioning systems too low. As many as 222 travellers $(71.8 \%)$ did not feel warm during the day and $249(80.6 \%)$ responded similarly about conditions at night. Only 17 tourists (5.5\%) felt uncomfortably warm indoors during the day and only 9 tourists $(2.9 \%)$ expressed the same opinion in reference to the night (see Table 4). It can be assumed that raising temperature by 4 to $5 \mathrm{~K}$ would shift the spectrum of responses toward the 'uncomfortably warm' end of the scale and yet a significant majority of tourists would be satisfied with such (warmer) conditions.

In the context of the questions on comfort/discomfort in actual conditions, it is interesting to see the responses to the question about the possibility of feeling comfortable without any help from air-conditioning. More than $2 / 3$ of all visitors $(211,68.3 \%)$ did not think that airconditioning was necessary for comfort indoors during the day, and even more of them $(234,75.7 \%)$ felt the same about the night. The number of people believing that air-conditioning was not necessary at all during the day was 60 or $19.4 \%$, and during the night 103 or $33.3 \%$ (see Table 4). It seems necessary to explain that the round-the-clock use of air-conditioning in a vast majority of tourist facilities in the tropics is normal. Hence it seemed justified that any doubts whether its provision should be continuous (or preference given to occasional provision, i.e. the 'sometimes' answer to the question on necessity for continuous use of air-conditioning) were qualified as negative responses.

It is worthwhile to stress that the survey was carried out in summer. M oreover, it was never suggested that powered air-conditioning systems could have an alternative. Despite this, almost half of all visitors surveyed $(144,46.6 \%)$ were ready to make their holidays in Cairns or a similar region being aware that air-conditioning would not be provided (see Table 4).

\section{DISCUSSION}

Care was taken during the survey not to suggest that alternatives to accommodation equipped with powered air-conditioning (HVAC) systems might be available. The overwhelming majority of interviewed tou-

\footnotetext{
${ }^{4}$ For the comfort perception (particularly, when appealing to one's recollections) there is probably only a negligible difference between, for instance, 'too warm' and 'much too warm' conditions. However, both would be remembered as uncomfortable
}

rists did not know that such a possibility existed. Their responses were related to the conditions that they found during their stay, and to a hypothetical possibility of coping with the climate inside buildings which, in fact, were not designed to run without HVAC systems. Despite this, a considerable number of visitors did not object to the suggestion that air-conditioners be removed, with quite a few expressing annoyance over the use of air-conditioning units.

It appears that tourist accommodation developers and operators are more in favour of air-conditioning systems than their users. ${ }^{5}$ People, by spreading all over the world in 'pre-technological' ages, have proven that they can cope with a large range of climates. Air-conditioning seems to be more a product of today's culture than a physiological necessity (Khan 1995, p. 13). ${ }^{6}$ As health hazards associated with living in air-conditioned (cooled) environments become more apparent, and as people begin to attach global-context criteria to energy use, one might expect that the current cultural standards would change. The need for integration of economic and environmental goals is presently widely accepted (Izmir 1995, p. 20). Some 'products' of living in the modern world, such as the same working-day schedule at all latitudes, will no doubt persist-forcing people who work in the tropics during the hottest part of the day to use HVAC systems. One could predict, however, introduction of 'environment-responsive' practices, phasing them out, eventually.

The survey demonstrated that at least 'leisure travellers' do not need air-conditioners to the extent they are provided. The results showed that an increase in indoor temperatures by a few degrees would be welcome by most of them, even before campaigning against 'condi culture' (as it becomes to be known, cf. Izmir 1995, p. 21) began. The reliance on air-conditioners should be reduced in tourist facilities. The desired climatic conditions are achievable with the support of passive means and it is only a matter of time before tourists learn about this. By then, Australia's coastal tropics could be at the forefront of a trend change, picking up environmental benefits all along the way (Izmir 1995).

\footnotetext{
${ }^{5}$ The situation resembles the recent campaign to introduce inflight smoking bans: initially, airlines-concerned about their profitability - strongly opposed the move in the wake of statistical figures showing a large proportion of the world population being smokers. A few years later, most airlinesconcerned about their profitability - have such bans in place

${ }^{6}$ For instance, Givoni (1994, p. 41) acknowledged 'cultural' differences suggesting boundaries of outdoor temperature and humidity within which comfort can be provided by natural ventilation separately for the categories of 'developed' and 'hot-developing' countries. People in the latter category supposedly better tolerate hotter and more humid conditions
} 
The findings of the survey are not conclusive and require further in-depth study. Some problems have only been touched and more investigation and research is needed to arrive at conclusive results. Nevertheless, the above findings should provide encouragement to building designers and developers to consider passive thermal design a viable option in Australia's tropical tourist resorts.

\section{LITERATURE CITED}

Auliciems A (1989) Thermal comfort. In: Ruck NC (ed) Building design and human performance. Van Nostrand Reinhold, New York, p 3-28

Editorial responsibility: Chris de Freitas, Auckland, New Zealand
Climatic Averages Australia (1975) Australian Government Publishing Service, Canberra

Givoni B (1994) Passive and low energy cooling of buildings. Van Nostrand Reinhold, New York

Izmir G (1995) Being seen to be green. Business-to-Business Review May, p 20-22

Khan M A (1995) Concepts, definitions and key issues in sustainable development: the outlook for the future. Paper for the International Sustainable Development Research Conference, $M$ anchester

McDowell (1966) Report on leasing and development of Queensland islands. University of Queensland, Brisbane

Mclntyre (1980) Indoor climate. A pplied Science Publishers, London

Selvamurthy W (1993) Physiological responses during 10 weeks sojourn in extreme Arctic cold environment. In: Proceedings of the 13th International Congress of Biometeorology, Calgary 2:508-521

Submitted: December 15, 1996; Accepted: J uly 6, 1999

Proofs received from author(s): September 7, 1999 